\title{
"Eles são cristãos como nós". O ser e o viver em comunidade na Serrinha
}

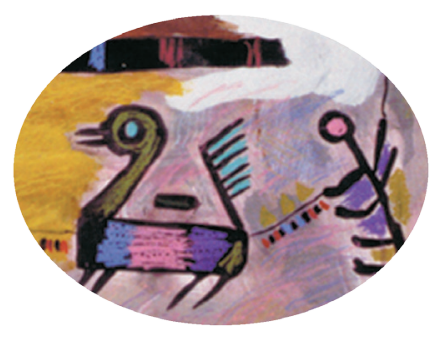

Camila Corrêa Félix*

\section{Resumo}

Durante os meses de trabalho de campo meu olhar esteve voltado para a existência de um mundo encantado no fundo das águas e para a forma pela qual a Serrinha, comunidade ribeirinha da Amazônia paraense, teoriza essa existência. Procurei investigar como o encante funda diversos âmbitos na vida da comunidade como a questão do sangue menstrual, aos elementos que fazem parte de um mundo em constante relação com as forças naturais e espirituais e que revelam práticas que suscitam uma conceituação da natureza não separada a priori da cultura. O material etnográfico em questão pretendeu "costurar" para o leitor as narrativas de alguns pontos de vista encontrados em campo.

\section{Palavras-chave: Comunidade; doença; sangue; Amazônia.}

\begin{abstract}
During the months of fieldwork my attention was focused on the existence of an enchanted world localized at the bottom of the river and on the manner through which the Serrinha, an Amazonian riverain community, theorizes about it. I tried to investigate how does it provides the ground for many aspects of the community's life like the menstrual blood question, and the elements that compose a world constantly related to the natural and spiritual forces and that reveals practices that involves a theory of nature not separated from culture. The ethnographic data tried to "sew" for the reader the narratives of diferents points of view found in the fieldwork.
\end{abstract}

* Mestranda do Programa de Pós-graduação em Sociologia e Antropologia da Universidade Federal do Rio de Janeiro (UFRJ). E-mail: camilacorreaf@yahoo.com.br 


\section{Keywords: Community; disease; blood; Amazônia.}

\section{Os Grupos Sociais e a Antropologia}

Ao longo da história da etnologia alguns modos de vida de regiões etnográficas específicas foram eleitos como modelos de organização social que permitiam assegurar certa previsibilidade, por meio do conhecimento de seu funcionamento, a sociedades que apresentavam teorizações e práticas muito distintas do modelo ocidental compartilhado pela maior parte dos antropólogos. Dessa forma, grupos corporados, linhagens e alianças de casamento passaram a ser exportados da África e Melanésia para grupos indígenas estudados pela disciplina. Anthony Seeguer, Roberto da Matta e Eduardo Viveiros de Castro destacaram de forma muito esclarecedora que os povos indígenas da América do Sul partilham de uma forma especialmente rica de elaborar sua noção de pessoa. A constituição do ser estaria referida, principalmente a corporalidade "enquanto idioma simbólico focal". O que esses autores defendem é que a forma como as sociedades indígenas sul-americanas enfatizam a produção e transformação dos corpos possibilita a compreensão de sua organização social e cosmológica. O fato de muitas etnografias terem tratado de temas a respeito da corporalidade, principalmente nas décadas de 1960 e 1970, mostra que para alcançar a estrutura social, nesses casos, os estudiosos necessitaram recorrer a esses aspectos. Os autores, entre outras coisas, apontam para a necessidade de tratar a noção de pessoa das sociedades estudadas como categoria. Isso porque muitas vezes esse tipo de formulação nativa costuma ser exposto a uma crítica com base nas concepções que o antropólogo carrega do que seja um indivíduo e uma sociedade, sendo considerados como ideologia.

Essas proposições dos autores, além se consistirem num marco da sistematização de uma noção de pessoas, particular dos ameríndios sulamericanos, propõe a nós, antropólogos, o profícuo exercício de submeter às concepções que nós levamos a campo e que legitimam nossos trabalhos científicos a uma crítica tão dura quanto a que submetemos a realidade que está diante de nossos olhos. Por que não nos perguntarmos que tipo de crítica às categorias nativas põem as categorias nativas da antropologia a respeito da ideia de indivíduo e a forma pela qual ele foi construído como necessariamente oposto à sociedade? Na leitura dos autores e com base num vasto material 
etnográfico, no que tange às sociedades ameríndias da América do Sul, a ideia de indivíduos como "agregados de papéis sociais estruturalmente prescritos" ou simplesmente como construções variáveis de grupo para grupo não se aplicam.

Ainda, é importante perceber que, como apontam os autores, essa ideia de indivíduo como ser portador de direitos e que deve cumprir deveres para o bom funcionamento da sociedade implica separação entre esses dois entes como distintos. $\mathrm{O}$ indivíduo nesse modelo é um obstáculo ao bom funcionamento da sociedade, já que esse ser ideal consciente de seus direitos e deveres é a figura proeminente do idealismo ocidental. Com base numa ideia de ordem e coesão social como supressão dos conflitos sociais o modelo euro-americano de sociedade representado em grande medida por antropólogos, missionários e viajantes procurou grupos sociais coesos e integrados em lugares que, no mais das vezes, não compartilhavam de valores como integração social e organização político-jurídica da forma como conhecemos.

Num texto de 1974, Roy Wagner, antropólogo americano que desenvolveu trabalho de campo entre os Daribi da Nova Guiné, assinala que a antropologia social orientou durante muito tempo seus esforços de pesquisa pela ênfase dada por Émile Durkheim aos aspectos sociais e coletivos que garantiam a existência dos grupos sociais como todos coesos e organizados. Segundo Wagner, Durkheim foi o responsável pela fundação de uma "ciência da integração social" que logrou analisar as formas pelas quais as associações humanas e a sociedade em si se mantinham como unidade, como coisa social.

Mais tarde, Radcliffe-Brown alcançou o êxito ao analisar as sociedades por suas instituições, assim como Durkheim, mas destacando como principal o entendimento da função de cada uma delas. A teoria antropológica decorrente chamada de funcionalismo elegeu, como esclarece Wagner, o domínio da jurisprudência e seus conceitos de propriedade, leis e direitos para analisar as coletividades e como elas funcionavam. Dessa forma, esses conceitos que ganharam força a partir do Iluminismo europeu foram transpostos para outras culturas "como se" elas funcionassem da mesma forma. Foi seguindo essa prerrogativa que os grupos de descendência se tornaram centrais à compreensão do funcionamento e integração das sociedades. Seguindo o desenvolvimento da disciplina, Roy Wagner garante que tanto o funcionalismo britânico quanto o estruturalismo francês tinham como objetivo principal a descoberta de uma 
ordem sistêmica dentro da cultura que eles identificassem com a forma como a cultura funciona ou como está conceitualmente articulada. Assim, ele questiona que a noção de grupo social seja indispensável à tradução e compreensão das mais diversas sociedades e pergunta se essa noção "não é uma descrição vaga e inadequada de algo que poderia ser mais bem representado de outra maneira" (1974: 102).

O pensamento ocidental foi erigido sobre a ideia da semelhança, da representação. A antropologia por diversas vezes ao longo de sua história pôs-se diante de um espelho ao confrontar-se com outras culturas. Ao ver refletida uma imagem diferente de si, criou metáforas. Veja que a metáfora é a pressuposição da existência de uma semelhança e a substituição de uma coisa por outra utilizando esse critério. Nesse jogo, o antropólogo é o árbitro. É ele quem decide o que parece com o que, é ele quem define, classifica e representa o que as outras pessoas fazem. Nesse sentido, é elevado a uma posição transcendental, ele tem sua cultura que está em relação com outra, mas essa igualdade é aparente, já que ele é também aquele que dita os termos dessa relação.

$\mathrm{Na}$ gramática de Wagner, o mundo ocidental opera sobre um modo de simbolização coletivizante ao passo que povos tribais, camponeses e tradicionais, operam sob um modo de simbolização diferenciante. ${ }^{1}$ No primeiro, os impulsos diferenciantes são suprimidos por um esforço de coletivização. A diferença é algo que deve ser suprimido pelo social, reino das similitudes e da conciliação (pelo menos para os ingleses), não que as diferenciações cessem de pulular em movimentos não identificáveis, mas são objetificadas, capturadas, molarizadas. ${ }^{2} \mathrm{~A}$ lógica diferenciante opera por contraste, segundo uma dialética entre a invenção e a convenção, há um conjunto básico de convenções que forma um terreno propício para improvisações, criações. Sob as semelhanças são erigidas as diferenças ${ }^{3}$ (WAGNER, 1981). Para Wagner, as culturas devem ser entendidas como variações de uma cultura entendida como fenômeno humano e é a partir da experiência de modos de cultura diferentes (dos nossos) é que (nosso) modo de vida precipita o que há nele de construído e deixa de ser universal. Ou seja, as culturas só se atualizam em relação. Essa operação é do que se trata a antropologia.

A peculiaridade da disciplina está na impossibilidade de exterioridade com relação ao objeto de estudo. Ela não é algo que existe anteriormente, 
é algo que se constrói em ato. Ao se propor a estudar outras culturas, o antropólogo não pode se despojar da sua. O equívoco repousa no delinear fronteiras pela criação de contrastes com efeito de suscitar um contexto geral. Os grupos assumiriam o caráter de abstração assim como outras categorias como tempo e espaço que ganham materialidade somente a partir das distinções arbitrárias de nossos relógios e calendários. "Tomar o modelo como idêntico à matéria leva ao estilo de construir a realidade sob a impressão de que se a está descobrindo ou prevendo" (WAGNER, 1974).

\section{O Ser e o Viver em Comunidade na Serrinha}

No presente trabalho opero com uma categoria que durante a experiência em campo me mostrou operar numa lógica "diferenciante". Isso porque é povoada por seres em relação que não ocupam posições fixas de sujeito, objeto, natureza ou cultura. Essas diferenciações existem, mas sua configuração não é definitiva. Por isso falo de comunidade apesar de ela relacionar-se de várias formas com várias outras comunidades, assim como terem uma vida muito próxima da cidade e algumas pessoas envolvidas com a articulação do movimento social transitarem por muitas cidades do Brasil.

Minha pesquisa é desenvolvida em uma comunidade de negros localizada na Amazônia, noroeste do Pará, a duas horas de barco da cidade de Oriximiná. Essa comunidade se autodesigna remanescente de quilombo e se encontra, como comentado acima, articulada a outras comunidades quilombolas em âmbito nacional.

Em trabalho de campo realizado nos meses de agosto e setembro de 2005 e fevereiro de 2009, pude perceber algumas questões que suscitaram para mim uma reflexão acerca da ideia de comunidade em marcha nesse caso. Central para essa reflexão foi a questão do papel do corpo como portador das perspectivas diversas e como motor da engrenagem hidráulica que movimenta a comunidade tal como é inventada por aqueles que a povoam.

Essa questão está posta em diversos momentos da vida em comunidade e por elementos que saltam como fundamentais ao bem-estar e ao viver junto com os outros. A posição do sangue, as restrições alimentares e os resguardos são alguns desses elementos que compõem as concepções nativas acerca de doenças e vitalidade. Pude perceber que a maior parte das restrições que dizem 
respeito ao sangue, como proibição do banho de rio de mulheres menstruadas e que tiveram filho havia menos de oito dias, engendra a existência de seres encantados que vivem no fundo do rio, em uma cabeceira localizada bem em frente à comunidade chamada Ponta do Cação. Tudo se passa de forma a fazer crer que o encante é um outro mundo que o da superfície, mas é de certa forma análogo a este, como se fossem duas linhas paralelas que apontam para direções opostas, mas que se entrecruzam em pontos de convergência possíveis. O mundo do fundo é tal qual o da superfície, existe uma cidade, e se ouvem os cantos entoados em suas festas. No fundo, os encantados são "cristãos como nós", mas podem assumir a forma que lhes aprouver, sendo muito frequente que se transformem em animais. Quando animais, os encantados oferecem um perigo constante para os humanos, o de transformação somática. Se encantados, os humanos passam a viver no mundo do fundo e pela ingestão de sua comida, criam guelras tais quais as dos peixes nunca mais retornando para o convívio dos parentes. A maior de todas as ameaças, porém, é a olhada de bicho. A "judiação" de bicho do fundo provoca doenças em crianças, e mudanças no comportamento dos adultos que podem passar a se comportar como animais, ou desenvolver um medo ou uma raiva inexplicável. Essas consequências são atribuídas a uma espécie de vingança desses bichos contra o fato de a mulher ter ido "lavar aquele sangue" no rio. Não é uma vingança, porém, contra a mulher que sangra e sim contra a comunidade.

O encante, dessa forma, é uma cidade subaquática que funciona da mesma forma que a da superfície. Aqueles que oferecem a pior ameaça às pessoas, aqueles que podem levar seus parentes do convívio social e que fazem adoecer suas crianças vivem num mundo tão social quanto o dos humanos. A lógica da predação na Amazônia é matéria de muitos estudos e foi amplamente discutida por autores como Pierre Clastres e retomada mais tarde por Eduardo Viveiros de Castro.

Assim como no que diz respeito ao significado do viver em sociedade, o mundo ocidental erigiu formas, que se tornaram hábitos de pensamento muito arraigados em suas culturas, de se perceber a relação entre o "eu" e o "outro". Podemos dizer, grosso modo, que essas entidades existem na cosmologia ocidental em função de "ego", como fechadas em si mesmas e postas numa relação que lhes é exterior e assumindo posições relativas. Nesse modelo perceptivo clássico, um sujeito individuado está posto diante de um 
objeto a ser percebido, compreendido. Ambos separados um do outro formam o par conceitual que funda o modelo de percepção ocidental e que existe em várias outras oposições como natureza e cultura, por exemplo.

Segundo Eduardo Viveiros de Castro, nessa tradição ocidental toda relação com “Outrem” está pressuposta pela relação do homem consigo mesmo. Tudo se passa como se o vínculo social estivesse fundado na autorrelação como modelo. Assim, essa mesma tradição teria na figura do Amigo uma espécie de "expressão prototípica" de "Outrem". Nesse sentido, o Amigo seria somente outro momento do eu, que acaba por ser a condição de possibilidade do pensamento. Portanto, a pergunta que a antropologia deve se colocar é: O que acontece quando ao invés do Amigo é a figura do Inimigo a expressão que funda as relações sociais? O que acontece quando é a lógica da predação e não $\mathrm{da}$ afinidade que rege a vida social?

A conceito de "Outrem" parece fornecer um instrumento interessante de tradução do contexto da alteridade amazônica. Segundo Viveiros de Castro, Outrem não é um Outro para o Eu, e sim a condição de possibilidade da relação, o palco no qual ela se realiza. Com isso, o autor pretende distinguir a alteridade ameríndia de uma ideia de intersubjetividade na qual Eu e o Outro funcionam como conteúdos da forma sujeito. "Outrem é uma multiplicidade virtual de onde emergem todo Eu e qualquer Outro” (VIVEIROS DE CASTRO, O possivel nativo: o outro sentido). Nesse contexto, não é a semelhança que funda a relação e a relação consigo mesmo não é a primordial.

Esse conceito aparece na obra de Gilles Deleuze e Félix Guattari como uma condição do campo perceptivo. A possibilidade de existência daquilo que não percebemos atualmente é a presença virtual de um Outrem, a sua figura garante um campo de possibilidades além da percepção atual. "Outrem, porém, não é ninguém, nem sujeito, nem objeto, mas uma relação absoluta que determina a ocupação das posições relativas de sujeito e objeto a personagens concretos" (VIVEIROS DE CASTRO, 2005). Outrem não é, dessa forma, um ponto de vista particular, mas a possibilidade de que haja ponto de vista, é um conceito de ponto de vista.

A questão do perspectivismo está posta na formulação acima assim como sua relação com a ideia da alteridade ameríndia. Que mundos são possíveis onde o ponto de vista do inimigo é entendido como "determinação transcendental"? Onde o inimigo é parte da estrutura do pensamento e, sendo 
assim, pode ser visto por sua positividade? Muito importante também para a presente reflexão é a questão: Quais conceitos de diferença e semelhança esse universo de perspectivas cambiantes engendra?

Os encantados viram gente em festas de padroeiro que acontecem no barracão da Serrinha. Nessas ocasiões diz-se que dançam a noite inteira e somem no raiar do dia. Quando gente, eles podem encantar aqueles de quem "se agradam" levando-os consigo. É importante ressaltar que os humanos viram encantados quando passam a compartilhar de sua vida em comunidade e isso acontece no momento em que começam a comer da mesma comida, e da mesma forma deixam de ser humanos por não participarem mais das festas, não caçarem, nem pescarem juntos, nem compartilharem mais os fluidos que compõem sua existência social.

O sangue assim como descrito por inúmeras etnografias amazônicas engendra transformações que são consideradas centrais por aqueles que estão expostos a elas. O sangue pós-parto e menstrual é cercado de cuidados e proibições. Não é só o rio que a mulher deve evitar durante esse período, mas deve observar restrições alimentares e espaciais. Mulheres que sangram não podem comer um animal que foi abatido com a ajuda de um cachorro caçador. Nesse caso, se a mulher comer a caça, o dono do cachorro e o próprio podem ficar "panema", ou seja, não conseguem mais caçar. Segundo explicações que recebi em campo, "não é que ele não consiga caçar, é que a caça não vem pra ele". É como se a possível presa sentisse o odor do sangue e fosse repelida. Inúmeros são os momentos em que homens e mulheres menstruadas devem manter certa distância um do outro. Um dos filhos do grande curador da comunidade e arredores, Baldoíno Melo, disse-me que não desenvolveu o dom de seu pai "porque andava muito no rastro de mulher menstruada".

O tema da menstruação e as restrições que a cercam também inspirou algumas reflexões antropológicas que o definiram como decorrente da ideia de pureza que esses povos ditos primitivos compartilham. Ou seja, em alguns trabalhos, como o de Mary Douglas intitulado Pureza e Perigo: Ensaio sobre as noções de poluição e tabu, a relação estabelecida entre o sangue menstrual e as pessoas, suscita uma ideia de contágio dos homens pelo contato com as mulheres em estado impuro. Só que mais uma vez podemos nos perguntar de quem é a obsessão pela ordenação das coisas, se nossa ou das chamadas sociedades primitivas. E ainda se os modos de ordenação não encontram 
muitas possibilidades em diferentes contextos. Assim, creio que essa noção de perigo que emana da mulher e contamina aqueles à sua volta não é corroborada pela realidade em questão. Beth Conklin explora o método comparativo ao pôr lado a lado ideias melanésias e amazônicas a respeito do sangue. Segundo a autora, o corpo das mulheres e a reprodução servem como metáfora à reprodução social. Argumenta que o sangue dos homens guerreiros em muitas comunidades amazônicas e melanésias também é cercado de restrições. Assim como os ritos femininos e masculinos, nos casos em que estuda, não podem ser analisados isoladamente sendo que não raro estão interligados. Parece então não ser a mulher simplesmente a fonte de poluição, nem a contaminação é tal qual como se pode ser infectado por uma bactéria ou vírus. Como se existisse um sujeito que age e outro que sofre a ação. A manutenção do controle do fluxo sanguíneo é matéria de responsabilidade de toda a comunidade.

Uma outra indicação preciosa que a etnografia oferece nesse sentido é a existência de um princípio gerador: a maternidade. Tudo o que é vivo tem uma mãe. Uma pedra, um lugar, um igarapé são notadamente vivos e contam com a proteção de uma mãe que os acolhe. Esse fato implica que tudo o que é vivo age, dessa forma, o cosmos é formado por sujeitos possíveis que sofrem e exercem uma ameaça constante que quase sempre corresponde ao tornar-se outro. Nesse ambiente em que todos os seres compartilham da relação mais primordial existente entre os humanos (é notável a importância da relação de maternidade entre as pessoas na Serrinha) a própria ideia da relação com aquele que oferece ameaça é totalmente afetada. Os encantados, que poderiam ser relegados na tradição de pensamento ocidental ao reino do sobrenatural e os animais, rios e igarapés ao da natureza, são tão sujeitos quanto os humanos. A relação com os inimigos é tão social quanto qualquer outra.

As indicações de autores como Christopher Crocker e Luísa Elvira Belaunde são instrumentos produtivos na análise da questão do sangue nesse caso, pois ao que parece o sangue traz uma situação de perigo transformacional que deve ser controlado por meio de dieta e reclusão. A situação de perigo à qual está exposta a mulher pelo excesso de sangue se estende a tudo à sua volta. Assim como ela se torna outra quando sangra, o clima, os rios, a mata e as outras pessoas também podem ser transformados. De acordo com Crocker, o "mecanismo hidráulico" do sangue circula dentro e fora do corpo, unindo os corpos de pessoas que estão em contato umas com as outras. Tanto homens 
quanto mulheres teriam de observar a regulação de seu fluxo sanguíneo e a não mistura entre eles para que haja um equilíbrio entre a fertilidade e a ameaça trazida por ele. Ao mesmo tempo, se o que dá poder aos homens é a possibilidade de manipular espíritos para causar o efeito desejado em outras pessoas, como no caso de feitiços, a menstruação faz da mulher poderosa também, e da mesma forma consciente e preparada, já que é responsável por controlar, por meio de banhos, dietas, remédios e reclusão, os fluxos de força e perigo, vitalidade e doença que atingem a comunidade como um todo.

O sistema que envolve a manutenção do fluxo sanguíneo e da vitalidade e perigo que emanam dele é complexo. No caso de comer a caça do cachorro, a mulher pode perder o filho que carrega e até morrer se o dono do cachorro preparar um banho para curar a panemisse. Dona Miraci me contou um caso ainda mais complicado, ao saber que a carne que tinha comido era caça de cachorro, foi falar com o dono do cachorro. Ele em resposta disse que, além de não "empanemar" o cachorro, ela ainda ia melhorar o seu potencial de caçador. Pediu para que ela colocasse a barra de sua saia no focinho do cachorro e mordesse três vezes seguidas. Dona Miraci disse que depois disso o cachorro caçou até onça. Nesse caso o tal homem era considerado índio, daí decorreria seu conhecimento sobre esse tipo de feitiço. Mas na Serrinha podese dizer que todo mundo sabe "mexer com alguma coisa".

Há uma série de conceituações sobre doenças e aqueles conhecidos por saber administrá-lo. A mãe do corpo fora do lugar, o quebranto e a desmentidura, junto com a olhada de bicho, a panemisse e os feitiços em geral são as principais. Assim como tudo a nossa volta, o corpo das mulheres também tem uma mãe. "Sem essa mãe do corpo nós não é nada", disse-me Maria Odília certa vez. Ela fica na altura do umbigo, palpitando no centro da barriga e dependendo do que a pessoa coma pode sair de sua órbita, "aí a pessoa fica tonta, cansada". Nesse caso, mais de uma pessoa na comunidade é conhecida por saber puxar a mãe do corpo, faz-se uma massagem de baixo para cima para que volte para o lugar certo. O principal sintoma da desmentidura é a febre. Se uma pessoa apresenta uma febre intermitente sem outra razão aparente, quase sempre essa possibilidade é levantada. Nesse caso, é necessário procurar alguém que saiba puxar desmentidura. Em minha última ida a campo acompanhei uma família que foi levar a filha para ser puxada por uma parenta. A mulher me disse que aprendeu a puxar "naturalmente". Pegou sebo de carneiro (andiroba também 
funciona), pôs a criança no colo e começou a massagear seu corpo enquanto os outros conversavam. Ao massagear um ponto das costas, a criança começou a chorar. A mulher disse que era ali, ateve-se àquele ponto por um tempo, depois parou. Já o quebranto é um mal infantil que pode ser decorrência de feitiço e olhada de bicho. Essa última acontece quando uma mulher menstruada vai tomar banho de rio, os bichos do fundo, irritados, "judiam” daqueles mais fracos, que não sabem orações para se proteger. Muitas vezes ao sofrer olhada de bicho a pessoa passa a se comportar como animal.

As conversas sobre doenças são muito frequentes e para o nosso olhar parecem beirar à hipocondria. São inúmeras as receitas de remédios caseiros feitos com ervas e as restrições alimentares. Nenhum alimento, porém, é maléfico isoladamente, as combinações é que não funcionam bem. Geralmente essas restrições são formuladas assim: "Fulano não pode comer comida seca", ou "castanha com taperebá é veneno" ou ainda "vinho de castanha com carne salgada faz mal pra malária". Existe um conceito nativo que designa alimentos que são perigosos sob determinadas condições, diz-se que são reimosos. Ao que parece, a medicina nativa não opera com conceitos absolutos, nem a ideia de veneno faz sentido isolada da sua relação com os outros alimentos ingeridos pela pessoa, o organismo daquele que o ingere e até com aqueles à sua volta. A doença, assim como nenhum outro mal, existe isolada das relações que a engendram, elas são sempre causadas por algo que a pessoa comeu, ou por um banho que alguém preparou (feitiço), ou pelo descuido de alguém, muitas vezes um mal é atribuído a atitudes de outras pessoas. Se um pai mata uma cobra durante a gestação da esposa, a criança pode nascer se "enrolando feito cobra". Matar macaco guariba nessas condições também não é bom, a criança pode nascer com alguma parte do corpo igual à de um macaco.

Beth Conklin destaca que pessoas e suas capacidades são criadas, nutridas e mantidas pelos fluxos de elementos tangíveis ou não entre seres humanos e outras categorias de seres como ancestrais, animais, espíritos e inimigos.

Júlio Cézar Melatti nos esclarece acerca dos Krakó que, por toda vida de uma pessoa, ela está ligada ao organismo daqueles que o geraram. As coisas se passam como se o organismo dos genitores continuasse a afetar o corpo de seu filho. As ligações entre os corpos dos indivíduos são sentidas durante os períodos em que eles apresentem um estado de debilidade ou fragilidade: o período após o nascimento, uma enfermidade grave ou após uma picada de 
cobra. Logo após o nascimento de uma criança, seu pai ou pais biológicos e sua mãe biológica devem respeitar, durante certo tempo, determinados tabus: estão proibidos de comer carnes, fumar, terem relações sexuais, de fazerem serviços pesados, de falarem em voz alta; nesses primeiros dias após o parto os genitores só podem comer batata-doce, inhame, milho branco, coco-macaúba. $\mathrm{Na}$ comunidade estudada acontece algo parecido. O pai de uma criança recémnascida não pode fazer nenhum trabalho pesado, nem cortar nada com faca ou tesoura, pois o umbigo da criança poderia arrebentar. Esse fato de alguma forma desmistifica a ideia de um laço coextensivo biológico unindo somente mãe e filho que muitas vezes é utilizada para legitimar dualismos tipo: mulher é a esfera doméstica e o homem é a esfera pública.

Luísa Elvira Belaunde (2006) nos ensina que em algumas línguas amazonenses o pensamento significa lembrar os nossos parentes, sentir saudades deles e agir no sentido de lhes oferecer cuidados e sustento.

Bem, tentei demonstrar que a forma como conceituam e vivenciam as doenças revela um senso de comunidade que perverte a centralidade da definição de grupos sociais organizados pelo princípio da descendência biológica. A observação às restrições, as conversas sobre doença, a descentralização das capacidades curativas, as visitas regulares aos curadores conformam a construção dos corpos e da comunidade. O cuidar da sua saúde e dos outros é que constrói o pertencimento.

\section{Notas}

${ }^{1}$ A convenção estabelece distinções socialmente reconhecidas entre o inato e o construído, já a invenção opera as transformações, cria a cultura que a convenção objetifica de forma a torná-la inteligível. A base relacional entre convenção e invenção no pensamento de Wagner pode ser entendida como socialidade, mas também pode ser entendida como linguagem, cosmologia, sistema etc.

${ }^{2}$ Lembrando que: “...e se é verdade que o molecular opera no detalhe e passa por pequenos grupos, nem por isso ele é menos coextensivo a todo o campo social, tanto quanto a organização molar. Enfim, a diferença qualitativa das duas linhas não impede que elas se aticem ou se confirmem de modo que há sempre uma relação proporcional entre as duas, seja diretamente proporcional ou inversamente proporcional”.

${ }^{3} \mathrm{O}$ pensamento de Roy Wagner exerce forte influência sobre o que se convencionou chamar de multinaturalismo. O conceito desenvolvido por Eduardo Viveiros de Castro em colaboração com Tânia Stolze Lima enuncia, com base na etnografia em povos ameríndios, 
que o postulado do relativismo cultural segundo as culturas seria as respostas específicas dadas aos mesmos problemas naturais, é invertido nas sociedades em que a cultura aparece como fundo comum e as naturezas é que são diversas. Não são os pontos de vista sobre o mundo que variam e sim os mundos, eles mesmos. Essa ideia é da mesma natureza da proposta por Wagner já nas simbolizações coletivizante e diferenciante, o que está em jogo é: Sob que reino repousa o controle? E de que natureza ele é? Como opera? Em um caso o controle é exercido pelo social em nome da integração, no outro as relações são a atualização e a invenção da sociedade, então pode se dizer que o controle está no que é inventado a partir das convenções.

${ }^{4}$ Esse conceito foi inicialmente proposto no comentário de Gilles Deleuze ao Vendredi de Michel Tournier. Esse comentário está publicado em apêndice à Logique du sens (Deleuze 1969a: 350-72; ver também id. 1969b: 333-35, 360).

\section{Referências}

ALVES, P. C.; SOUZA, M. C. Saúde e doença: Um Olhar Antropológico. Rio de Janeiro: Souza Minayo, 1994.

BELAUNDE, Luísa Elvira. Viviendo Bien: Genero y fertilidad entre los AiroPai de la Amazonia peruana. Lima: Caaap, 2001.

- El Recuerdo de Luna, género, sangre y memoria entre los pueblos amazonicos. Lima: Fondo Editorial de la Faculdad de Ciencias Sociales, 2001.

- A força do pensamento, o fedor do sangue. Hematologia e gênero na Amazônia. Revista de Antropología, vol. 49, n. ' 1, São Paulo, 2006.

CLASTRES, Pierre. O Arco e o Cesto. In: A Sociedade contra o Estado. Rio de Janeiro: Editora Livraria Francisco Alves, 1990.

- Crônica dos indios guayaki: o que sabem os aché, caçadores nômades do Paraguai. Rio de Janeiro: Editora 34, 1995.

CONKLIN, B. Women's Blood, Warriors' Blood, and the Conquest of Vitality in Amazonia. In: Gender in Amazonia and Malanesia. An exploration of the comparative method. Edited by Gregor, T. A. University of California Press, 2001.

CROCKER, C. Bororo cosmology, natural symbolism, and shamanism. University of Arizona Press, 1985. 
DOUGLAS, M. Pureza e perigo. Ensaio sobre as noções de polvição e tabu. Lisboa: Edições 70, 1966.

DELEUZE, Gilles; GUATTARI, Felix. Mil Platôs: Capitalismo e esquizofrenia. Vol 4. São Paulo: Ed. 54, 1995.

LATOUR, B. Jamais Fomos Modernos. Rio de Janeiro: Editora 34, 1994.

LÉVI-STRAUS, C. Antropologia Estrutural Dois. O Feiticeiro e a sua Magia. Rio de Janeiro: Tempo Brasileiro, 1975.

LIMA, T. S. O Dois e seu múltiplo: Reflexões sobre o Perspectivismo em uma Cosmologia Tupi. Revista Mana, número 2(2):21-47, 1996.

MELATTI, J. C. Nominadores e genitores: um aspecto do dualismo Krakó. In: SCHADEN, Egon. Leituras de Etnologia Brasileira. São Paulo: Companhia Editora Nacional, 1976, p. 139 a 148.

VIVEIROS DE CASTRO, E. Os pronomes cosmológicos e o Perspectivismo Ameríndio. Revista Mana: Estudos de Antropologia Social, número 2(2):115-144, 1996.

. A imanência do inimigo. In: A inconstância da alma selvagem. São Paulo: Cosac \& Naify, 1996.

. O Nativo Relativo. Revista Mana: Estudos de Antropologia Social. 8(1):113-148, 2002.

. O possível nativo: o outro sentido. Publicado em wikia amaźne,

2005. 